\title{
Liver Progression GvHD
}

National Cancer Institute

\section{Source}

National Cancer Institute. Liver Progression GVHD. NCI Thesaurus. Code C126732.

An increase by two times the upper limit of normal for ALT, alkaline phosphatase, and total bilirubin. 